\title{
FORMACุÃO DE RECURSOS HUMANOS EM SAÚDE NO BRASIL: UMA REVISÃO INTEGRATIVA
}

\author{
Carine Vendruscolo* \\ Marta Lenise do Prado** \\ Maria Elisabeth Kleba***
}

RESUMO: A Revisão Integrativa da Literatura analisou temáticas de estudos relacionados à formação de profissionais orientada para o Sistema Único de Saúde, de 2001 a 2012. Para a busca, em outubro de 2012, utilizaram-se os descritores: "Formação de Recursos Humanos" and "Sistema Único de Saúde", em consulta ao portal Biblioteca Virtual em Saúde. Foram encontrados 86 trabalhos, e 30 contemplavam os critérios de inclusão, os quais foram analisados, identificando-se as dimensões temáticas: princípios e diretrizes do SUS como orientadores da formação; necessidades do usuário e dos serviços de saúde; e papel dos diferentes sujeitos e organizações na mudança. Confirma a importância da formação como operadora essencial das mudanças na prática dos trabalhadores da saúde. Recomenda-se a realização de pesquisas com vistas ao fortalecimento dos dispositivos de reorientação da formação e ao aprofundamento do debate.

Palavras-chave: Formação de Recursos Humanos; Sistema Único de Saúde; Educação Superior.

\footnotetext{
* Doutora em Enfermagem pelo Programa de Pós-Graduação em Enfermagem da Universidade Federal de Santa Catarina (UFSC); Professora da Universidade do Estado de Santa Catarina (UDESC), membro do Grupo de Pesquisa Educação em Enfermagem e Saúde (EDEN/PEN/UFSC) e do Grupo de Estudos sobre Educação e Trabalho (GESTRA/UDESC). E-mail: carine.vendruscolo@udesc.br

* * Doutora em Filosofia da Enfermagem pelo Programa de Pós-Graduação em Enfermagem da Universidade Federal de Santa Catarina (UFSC); Professora do Departamento de Enfermagem e do Programa de Pós Graduação da Universidade Federal de Santa Catarina (UFSC). E-mail: marta.lenise@ufsc.br.

** * Doutora em Filosofia pela Universidade de Bremen (Alemanha); Professora do Curso de Enfermagem da Universidade Comunitária da Região de Chapecó (Unochapecó). E-mail: Ikleba@unochapeco.edu.br.
} 


\section{FORMATION OF HUMAN RESOURCES IN THE FIELD OF HEALTH IN BRAZIL: AN INTEGRATIVE REVIEW}

ABSTRACT: The Integrative Review of Literature has analyzed issues related to the professional formation of member of the Brazilian National Health System, from 2001 until 2012. The search, collected in October of 2012, included the query terms "Human Resources Formation" and "Single Health System", and was performed by consulting the Health Library Virtual Portal. 86 studies were found and 30 of them contemplated the inclusion criteria for the search, which were analyzed and classified identifying the following themes: Health System principles and guidelines as formation determiners; User needs and health services needs and Role of different individuals and organizations in the change. It has confirmed the importance of training for guiding the changes in the practice of the health care workers. Further research is recommended in order to strengthen the devices of retraining and to deepen the debate.

Keywords: Human Resources Formation; Unified Health System; Higher Education.

\section{Introdução}

Há evidências quanto ao bom desempenho da Atenção Básica (AB) à Saúde na orientação de sistemas públicos, em especial no que diz respeito à produção de atos de cuidar de indivíduos e grupos sociais que favoreçam a integralidade, a humanização e a qualidade da atenção dispensada (MOROSINI; CORBO, 2007). No Brasil, o ideário da Reforma Sanitária, incorporado pela instituição do Sistema Único de Saúde (SUS), demandou dos serviços uma nova lógica no desenvolvimento das práticas dos trabalhadores, tendo a Estratégia Saúde da Família (ESF) como eixo estruturante da AB (ALMEIDA; SOARES, 2002).

Apesar das discussões sobre medidas de fortalecimento da política de saúde na direção de um modelo integral e promotor da saúde (BRASIL, 2006), permanecem problemas no campo da formação dos profissionais, revelando um distanciamento destes - com orientação biologicista e conteudista - em relação à práticas interdisciplinares e que favoreçam a (co)responsabilidade e os vínculos (inter)profissionais. $\mathrm{O}$ reflexo dessa formação ocasiona para o trabalhador o dilema de conviver com dois modelos antagônicos e dificulta o desenvolvimento de atividades, para além de suas reais aptidões e preparo.

Como medida de reversão desse cenário, aposta-se na formação de profissionais comprometidos com a construção da autonomia e do 
protagonismo de sujeitos e coletivos, valorizando as dimensões subjetiva e social das práticas de cuidado e de gestão em saúde (BRASIL, 2004a). As estratégias para essa medida convergem com a demanda do art. 200, inciso III, da Constituição Federal do Brasil, o qual refere que cabe ao SUS “ordenar a formação de recursos humanos" para a área da saúde (BRASIL, 1988). Contudo, a ocorrência de intentos constitucionais que atribuem à saúde a responsabilidade pelo ordenamento da formação não garante e nem significa que o setor, de maneira isolada, consiga cumprir essa missão (AMÂNCIO FILHO; VIEIRA; GARCIA, 2006).

Nesse sentido, o Ministério da Saúde (MS) constituiu estratégias de diálogo com o Ministério da Educação (MEC), buscando viabilizar o cumprimento do pleito constitucional. Tanto nos serviços, quanto nas escolas técnicas e universidades, foram tomadas medidas para reordenar a formação, a qualificação e o desenvolvimento dos trabalhadores da área da saúde, de forma a combater o modelo hegemônico. Esse novo olhar demandou a participação ativa do trabalhador na construção do SUS, além da valorização da dimensão criativa do sujeito em formação, inaugurando um novo patamar de articulação ensino-serviço ao aproximar o mundo da formação e o mundo do trabalho em saúde (ALMEIDA; SOARES, 2002).

Nas décadas de 1980 e 1990, foram iniciados os primeiros movimentos de aproximação desses mundos, com base nos pressupostos teórico-metodológicos apresentados pela Organização Pan-Americana de Saúde/Organização Mundial de Saúde (OPAS/OMS) para desenvolver ações de Educação Permanente em Saúde (EPS) (FERRAZ et al., 2012). Dentre esses movimentos, destacam-se o Projeto Larga Escala e, posteriormente, os Projetos de Capacitação em Desenvolvimento de Recursos Humanos de Saúde (CADRHU) e de Desenvolvimento Gerencial de Unidades Básicas do Sistema Único de Saúde (GERUS). Em 1996, o MS criou os Polos de Educação Permanente em Saúde da Família, com o objetivo de orientar as mudanças no modelo de formação dos recursos humanos (FERRAZ et al., 2012).

No intuito de adequar a formação na área de maneira coerente com as necessidades do SUS, foram aprovadas as novas Diretrizes Curriculares Nacionais (DCN) para os cursos da área da saúde, em 2001, as quais proporcionam as bases para essa reorientação no mundo do ensino. A exemplo das DCN para os cursos de graduação em enfermagem, a 
formação deve atender as necessidades sociais da saúde, com ênfase no SUS, garantindo que o cuidado seja prestado de forma integral, humanizado e com qualidade (BRASIL, 2001).

Em 2003, o MS evidenciou a preocupação em articular educação e regulação da força de trabalho nos serviços. Por meio de parcerias e do diálogo com o MEC e outros órgãos, o MS criou a Secretaria de Gestão do Trabalho e da Educação na Saúde (SGTES). Organizada em duas divisões - Departamento da Gestão da Educação na Saúde e Departamento da Gestão e da Regulação do Trabalho em Saúde - a SGTES desenvolveu programas para estruturar e fortalecer o processo de formação e de desenvolvimento de recursos humanos, com o objetivo de melhorar a qualidade e a resolutividade da AB (BRASIL, 2004b; HADDAD et al., 2008).

Em fevereiro de 2004, foi instituída a Política Nacional de Educação Permanente em Saúde (PNEPS), e, como ação estratégica para sua efetivação, foram reorganizados os Polos de Capacitação em Saúde da Família como Polos de Educação Permanente em Saúde para o SUS. Esses deveriam superar a fragmentação da educação na saúde, ao apoiar a integração entre o ensino e o serviço, entre a formação e a gestão e entre o desenvolvimento institucional e o controle social (FERRAZ et al., 2012).

A Portaria GM/MS n.1.996 de 2007 apresenta novas diretrizes e estratégias para a implementação da PNEPS, mantendo, contudo, em nível de estados e regiões, alguns pressupostos da Portaria anterior, como as necessidades de considerar especificidades regionais e investir no desenvolvimento para o trabalho em saúde, com vistas à superação das desigualdades regionais, além de considerar a capacidade já instalada de oferta institucional de ações formais de educação na saúde (BRASIL, 2004a; 2007a; FERRAZ et al., 2012).

Essa mesma Portaria define que a condução regional da política implicará na cooperação entre os Colegiados de Gestão Regional (CGR) - atualmente, designados de Comissões Intergestores Regionais (CIR) (BRASIL, 2011) - e as Comissões Permanentes de Integração EnsinoServiço (CIES), instâncias previstas no regulamento, que participam da formulação, execução, acompanhamento e avaliação de ações da EPS. As CIES devem ser compostas pelos gestores de saúde, gestores de educação, trabalhadores do SUS, instituições de ensino com cursos na área da saúde, por meio de seus distintos segmentos, e movimentos sociais liga- 
dos à gestão das políticas de saúde e do controle social no SUS (BRASIL, 2007a).

Na perspectiva da PNEPS, a cooperação técnica entre o MS e o MEC articula outras ações, denominadas estruturantes, relacionadas à reorientação da formação de profissionais da saúde, visando à integração ensino-serviço-comunidade, dentre as quais, destacam-se: fortalecimento das Escolas Técnicas do SUS; formação de Agentes Comunitários de Saúde, Auxiliares de Enfermagem, Técnicos de Saúde Bucal; Programa Nacional de Reorientação da Formação Profissional em Saúde (PróSaúde); Programa de Educação pelo Trabalho para a Saúde (PET-Saúde); Telessaúde; Universidade Aberta do SUS (UNA-SUS); Residência Multiprofissional em Saúde; Residência Médica; entre outros (HADDAD et al., 2008).

A lógica desses processos educativos prevê que as respostas às demandas para a educação e a formação podem ter mais êxito se apoiadas em metodologias problematizadoras, ancoradas na concepção pedagógica transformadora e emancipatória de Paulo Freire, tendo por base a identificação de necessidades de qualificação implicadas nos processos de trabalho em saúde. Requerem, portanto, ações integradas às redes de serviços de saúde e do controle social no setor. A transformação das práticas só é possível a partir da interação com a realidade e se dá por meio do desenvolvimento da capacidade de aprender, fazendo com que essa transformação se consolide (FREIRE, 2005), refletindo no perfil profissional.

Estudo sobre o alcance dos programas e políticas ordenadores da formação de profissionais de saúde no Brasil aponta limitado número de publicações no caráter de revisões sistematizadas sobre o tema. Recomenda esse tipo de pesquisa, a fim de analisar tais programas e/ou políticas, de forma a contribuir com sua implementação (FERRAZ et al., 2012). Esse aspecto justifica a revisão apresentada, a qual tem como objetivo analisar as temáticas de estudos sobre a formação de recursos humanos em nível de graduação, voltada para o SUS, na última década.

\section{Metodologia}

Trata-se de pesquisa exploratório descritiva, em base documental, de natureza qualitativa, baseada nos pressupostos da revisão integrati- 
va de literatura (GANONG, 1987), com foco na seguinte pergunta: quais são as dimensões temáticas dos estudos sobre a formação de profissionais de saúde orientada para o SUS, no Brasil, no período de 2001 a 2012?

O protocolo de pesquisa, elaborado e validado em fevereiro de 2012, seguiu as seguintes tarefas para a revisão: seleção da questão de pesquisa; definição de critérios de inclusão de estudos e seleção da amostra; representação dos estudos selecionados em formato de tabelas; análise crítica dos achados; interpretação dos resultados; e reprodução clara da revisão (GANONG, 1987). Adotaram-se como critérios de inclusão: trabalhos publicados no formato de artigos científicos (artigos originais, revisões sistematizadas, relatos de experiências, ensaios teóricos, reflexões); estudos nos idiomas inglês, português ou espanhol publicados no período de 2001 a 2012; trabalhos disponibilizados on-line, com os seguintes unitermos: "Formação de Recursos Humanos" and "Sistema Único de Saúde - SUS" evidenciados no estudo. Constituíram critérios de exclusão: estudos voltados à formação em outro nível que não à graduação na área da saúde; revisões bibliográficas não sistematizadas; cartas; resenhas; editoriais; publicações do tipo: livros, capítulos de livros, publicações de autoria governamental, boletins informativos, monografias, trabalhos de conclusão de curso, teses, dissertações, resumos, trabalhos oriundos de eventos, estudos que não estão disponibilizados on-line no formato completo para análise, estudos duplicados.

A busca livre de artigos foi realizada com base na consulta ao portal Biblioteca Virtual em Saúde (BVS/BIREME). Foi selecionado o item "pesquisa na bvs" com os descritores (sem aspas); selecionando o "método integrado", "todos os índices", "todas as fontes", garantindo a realização da busca em todas as bases que compõem a BIREME. No item "idioma" da coluna à esquerda do site, foram selecionados os idiomas: português, inglês e espanhol.

A busca primária dos estudos ocorreu em outubro de 2012 e percorreu o caminho apresentado na Figura 1. 


\section{FIGURA 1}

Fluxograma de seleção dos estudos que compuseram a revisão integrativa

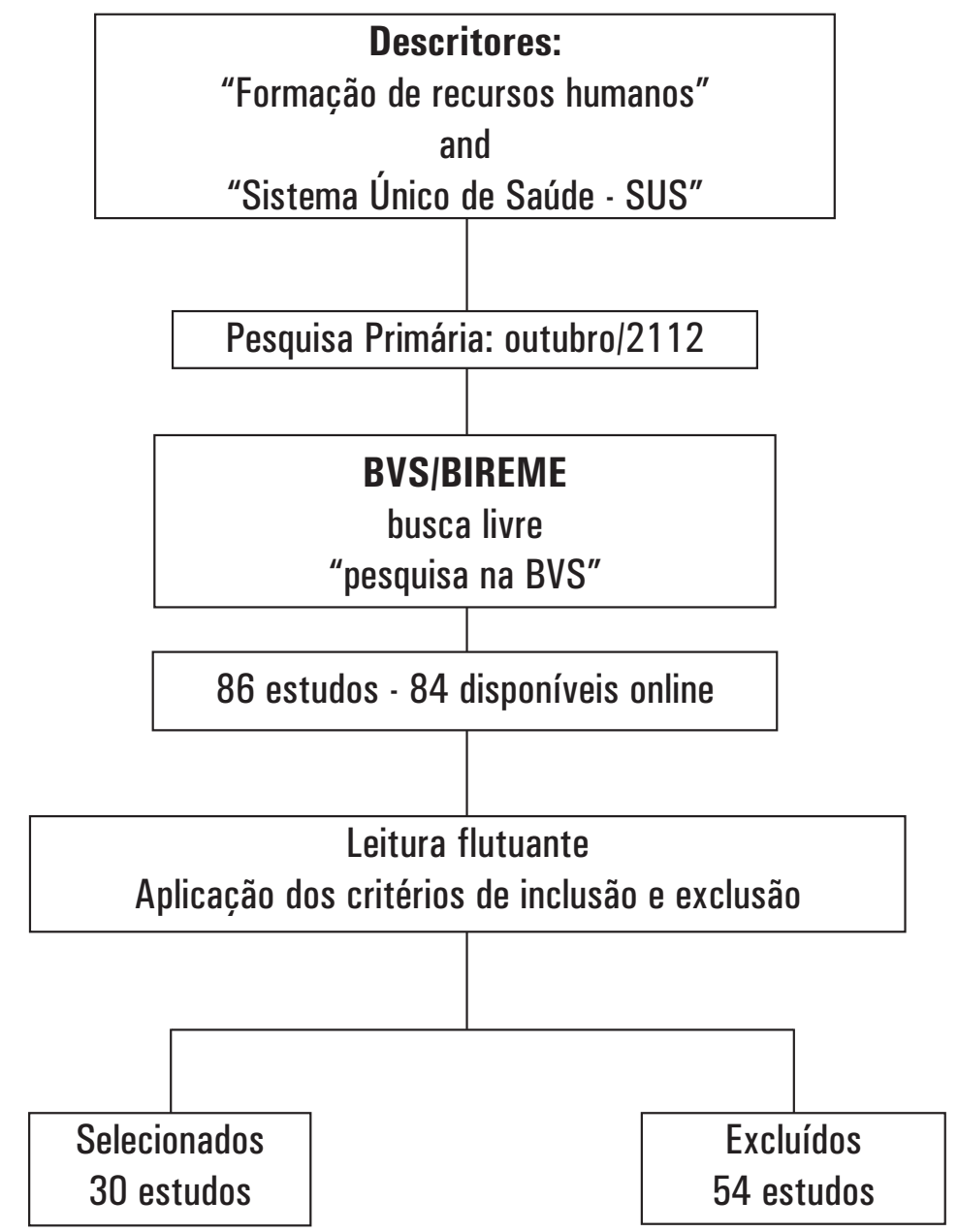

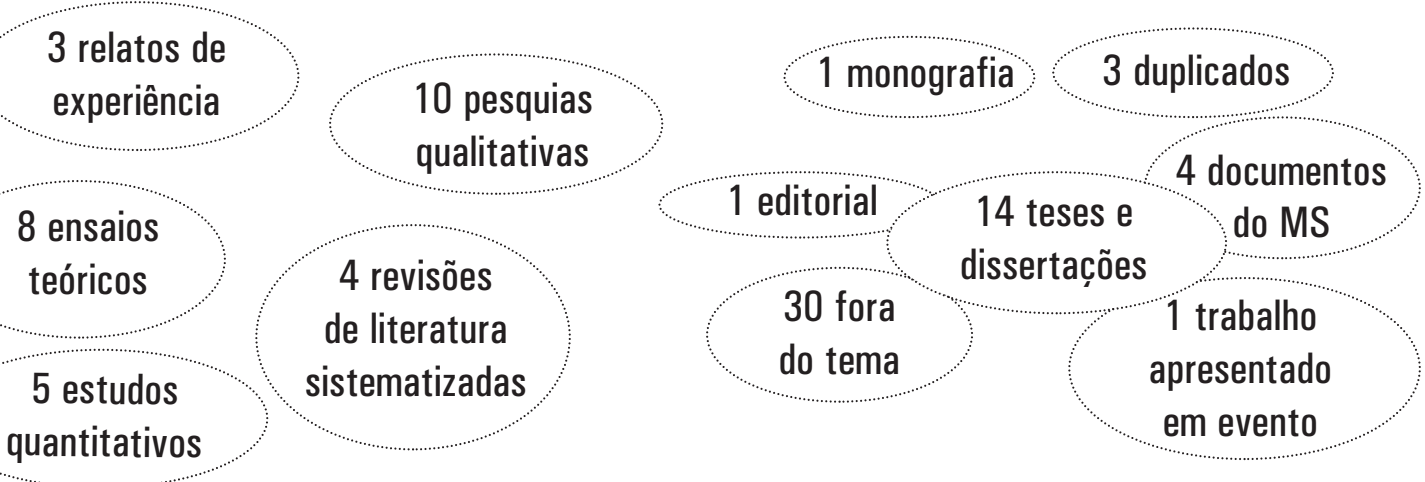


De um total de 86 artigos identificados, 84 estavam disponíveis on-line. Os estudos pré-selecionados para análise foram dispostos em uma matriz com as seguintes informações organizadas em pastas do Microsoft Word®: título, autores, periódico, ano, natureza do estudo, objetivos e principais achados/conclusões.

A análise dos achados foi realizada a partir da leitura minuciosa dos trabalhos na íntegra, com o objetivo de constatar a aderência ao objetivo desta pesquisa. No âmbito de cada item da matriz, as ideias foram agrupadas por similaridade, de modo a compor uma síntese narrativa e estruturar as "dimensões temáticas" dos estudos. Após novas leituras dos textos completos, outros estudos foram descartados, por não atenderem os critérios definidos.

A avaliação seguiu o modelo analítico de Ganong (1987), que orienta a revisão integrativa da literatura. Por esse motivo, não ocorreu o envolvimento direto com seres humanos, não sendo necessária a aprovação da investigação por um Comitê de Ética em Pesquisas com Seres Humanos.

\section{Resultados e discussão}

A tabela a seguir apresenta os 30 artigos selecionados e analisados, organizados segundo periódico e ano de publicação (Quadro 1).

\section{QUADRO 1}

Publicações sobre formação para o SUS, segundo periódico e ano

\section{TítULO}

E1. 0 que dizem a legislação e o controle social em saúde sobre a formação de recursos humanos e o papel dos gestores públicos, no Brasil

E2. 0 currículo integrado da Faculdade de Enfermagem UERJ: uma reflexão sobre a formação de recursos humanos para o SUS

E3. O SUS e a formação de recursos humanos

E4. Educação Permanente no contexto da enfermagem e na saúde

E5. A educação médica diante das necessidades sociais em saúde

E6. Pobreza, injustiça e desigualdade social: repensando a formação de profissionais de saúde

E7. Potencialidades da educação permanente para a transformação das práticas de saúde

E8. Educação Permanente: componente estratégico para a implementação da política nacional de atenção oncológica

E9. Formação de profissionais de saúde na perspectiva da integralidade

\section{PERIÓDICO}

Ciên. saúde coletiva

Rev. Bras. Enferm.

ACM arq. catarin. med.

Rev. Bras. Enferm.

Rev. bras. educ. méd.

Rev. bras. educ. méd.

Com. Ciências Saúde

Ciên. saúde coletiva

Rev. Bras. Enferm.
ANO

2002

2003

2003

2004

2005

2007

2007

2007

2007 


\section{TíTULO}

E10. Programas de Residência Médica em oncologia orientados por competência: trajetória de uma construção coletiva

E11. Significado do Programa Vivência e Estágios na realidade do

Sistema Único de Saúde para formação profissional na área de saúde

E12. Formação de recursos humanos para a Estratégia de Saúde da Família

E13. Administração em enfermagem: desvelando as bases conceituais, metodológicas e pedagógicas de seu ensino em João Pessoa/PB E14. Um olhar sobre a formação do enfermeiro/docente no Brasil

E15. Complexidade em Saúde da Família e formação do futuro profissional de saúde

E16. Percepção dos coordenadores de saúde bucal e cirurgiões dentistas do serviço público sobre o Sistema Único de Saúde (SUS)

E17. Formação profissional no SUS: oportunidades de mudanças na perspectiva da estratégia de saúde da família

E18. A formação em psicologia e o profissional da saúde para o SUS (Sistema Único de Saúde)

E19. Programa de aprimoramento profissional em Terapia

Ocupacional

E20. Reflexões sobre os desafios da Odontologia no Sistema Único de Saúde

E21. A formação de profissionais de saúde em instituições de ensino superior de Divinópolis, Minas Gerais

E22. Práticas de ensino-aprendizagem com base em cenários reais

E23. Opinião do graduando de Enfermagem sobre a formação do enfermeiro para o SUS: uma análise da FAEN/UERN

E24. Formação dos profissionais de saúde para o SUS: significado e cuidado

E25. A Odontologia no contexto do sistema único de saúde de Montes Claros, Minas Gerais

E26. Educação odontológica e sistema de saúde brasileiro: práticas e percepções de estudantes de graduação

E27. Integração "ensino-serviço" no processo de mudança na formação profissional em Odontologia

E28. Assistência farmacêutica no Sistema Único de Saúde (SUS): percepções de graduandos em Farmácia

E29. 0 PET-Saúde como ferramenta estratégica de implantação de um curso de Medicina em uma universidade pública: relato de uma experiência

E30. A formação de valores e a prática da atenção primária na saúde com estudantes de Odontologia
PERIÓDICO

Rev. bras. cancerol

Acta Paul Enferm

2008

Ciênc. cuid. saúde

2008

Ciênc. cuid. saúde

2008

Rev. Enferm. UERJ

2008

Interface comun. saúde

2009

educ.

Saúde soc.

2009

Trab. educ. saúde

2009

Arq. bras. psicol.

2009

Rev. Ciênc. Méd.

2009

Rev. APS

2010

Trab. educ. saúde

2010

Interface comun. saúde educ.

Esc. Anna Nery Rev. Enferm.

2010

2010

Saúde Soc.

2011

Arq Odontol.

2011

Arq Odontol.

2011

Interface comun. saúde educ.

2011

Interface comun. saúde educ.

2011

Rev. bras. educ. méd.

2012

Acta bioeth

2012 
De maneira geral, chama a atenção a escassez de publicações sobre o tema, sobretudo, em periódicos editados fora do Brasil. A partir de 2005, esse quadro se modifica, pois, nessa época, ganham status de política pública as ações voltadas à formação de recursos humanos direcionada aos desígnios do SUS.

Um quantitativo considerável de trabalhos trata da formação de recursos humanos na odontologia (seis estudos), seguidos por trabalhos que se referem à enfermagem (cinco estudos), medicina (três estudos), psicologia (um estudo) e farmácia (um estudo). Os demais estudos abordam a formação de recursos humanos orientada para o SUS, sem especificar a categoria profissional. Esse aspecto confirma a preocupação das diferentes áreas com a temática.

A maior parte dos estudos é referente a 2007, 2009 e 2011, conforme demonstra o Gráfico 1. Esse achado pode estar relacionado com os efeitos das Ações Estruturantes Interministeriais de Reorientação da Formação de profissionais da saúde, intensificadas a partir de 2005, com as propostas integradas entre as Secretarias de Saúde e as Instituições de Ensino Superior (IES) (HADDAD et al., 2008; BRASIL, 2007b). Outro fato que marcou esse período foi a revisão da PNEPS, em 2007, estimulando propostas integradas voltadas à Educação Permanente dos profissionais da saúde (BRASIL, 2007a).

\section{GRÁFICO 1}

Produção brasileira sobre formação para o SUS, segundo ano de publicação

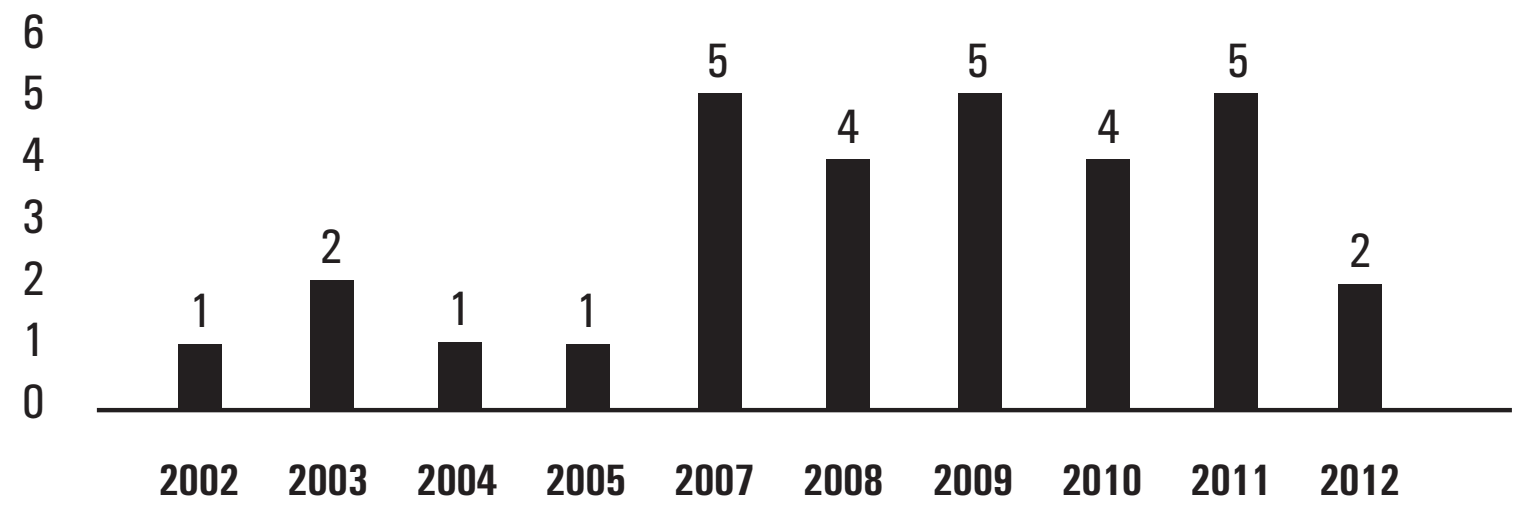

Fonte: BVS 2012. 
Evidencia-se uma forte tendência para a realização de estudos empíricos com abordagem qualitativa (10) sobre a temática, sendo apenas cinco com abordagem quantitativa. É expressivo o quantitativo de trabalhos publicados no formato de ensaios teóricos (oito), seguido de relatos de experiência (três) e de revisões de literatura sistematizadas (quatro), como ilustra o Gráfico 2.

\section{GRÁFICO 2}

Estudos brasileiros sobre formação para o SUS, segundo abordagem

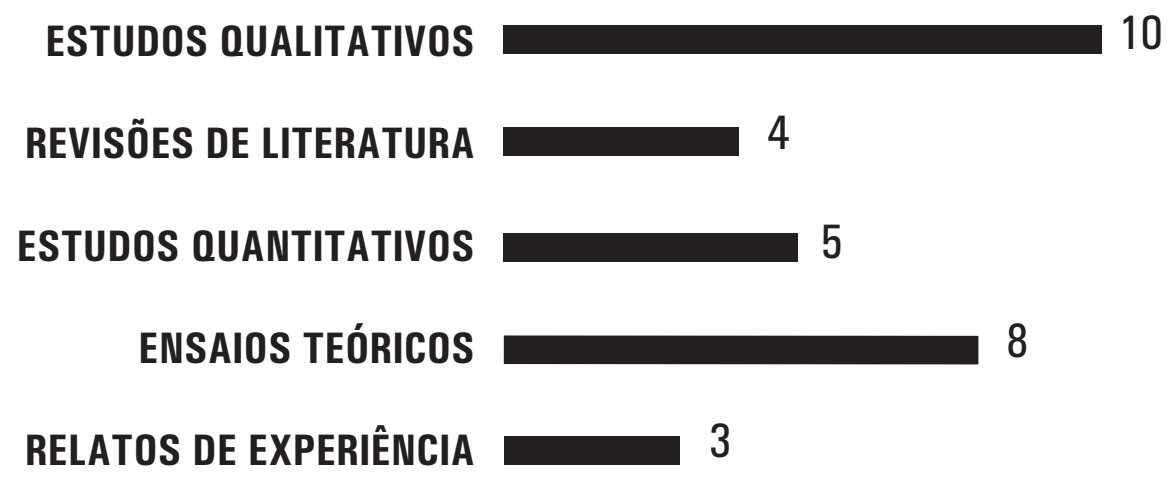

$\begin{array}{llllll}0 & 2 & 4 & 6 & 8 & 10\end{array}$

Fonte: BVS 2012.

A partir da análise dos achados, foram extraídas as seguintes dimensões temáticas (DT), tendo em vista o referencial teórico que norteou o estudo relacionado à formação de recursos humanos orientada para a lógica do SUS: DT1) Princípios e diretrizes do SUS como orientadores da formação; DT2) Necessidades do usuário e dos serviços de saúde; e DT3) Papel dos diferentes sujeitos e organizações na mudança.

O quadro a seguir (Quadro 2) ilustra o panorama geral dos resultados, por meio de uma listagem das principais temáticas identificadas, suas características e estudos que se destacaram em cada uma delas. $\mathrm{Na}$ sequência, apresentam-se as referidas DTs e a análise mais detalhada dos respectivos estudos que as compõem. 


\section{QUADRO 2}

Panorama síntese dos resultados de acordo com os estudos e respectivas dimensões temáticas às quais pertencem

\section{PANORAMA SÍNTESE DOS RESULTADOS}

\begin{tabular}{|c|c|c|}
\hline $\begin{array}{c}\text { Dimensões Temáticas (DT) } \\
\text { DT1 - Princípios e diretrizes } \\
\text { do SUS como orientadores } \\
\text { da formação }\end{array}$ & $\begin{array}{c}\text { Características } \\
\text { Mudanças no mundo do trabalho implicam movimentos } \\
\text { que favoreçam o exercício da cidadania, os quais se iniciam } \\
\text { no mundo do ensino. } \\
\text { São considerados requisitos para a formação aspectos como } \\
\text { solidariedade, vínculo, trabalho em equipe, humanização e } \\
\text { capacidade de dialogo. } \\
\text { Integralidade abordada como princípio fundamental para } \\
\text { reorientar a formação e repensar processos de trabalho. } \\
\text { Currículos e Projetos Pedagógicos podem ser espaços } \\
\text { de conscientização sobre a política. } \\
\text { Ações Estruturantes Interministeriais como importantes } \\
\text { movimentos voltados às mudanças da formação, por meio } \\
\text { do estímulo a competências e habilidades dos sujeitos. }\end{array}$ & \begin{tabular}{ccc}
\multicolumn{2}{c}{ Estudos (E) } \\
E9 & E12 & E15 \\
E17 & E18 \\
E19 & E23 \\
E25 & E30
\end{tabular} \\
\hline $\begin{array}{c}\text { DT2 - Necessidades do } \\
\text { usuário e dos serviços } \\
\text { de saúde }\end{array}$ & $\begin{array}{l}\text { Adequar a educação/formação em saúde ao contexto } \\
\text { das necessidades sociais. } \\
\text { Necessidade de um perfil profissional generalista e } \\
\text { conhecedor da comunidade/realidade. } \\
\text { Inserção dos estudantes no cenário das práticas do SUS } \\
\text { favorece a evolução do conhecimento. } \\
\text { Ações Estruturantes Interministeriais como dispositivo } \\
\text { favorável à integração ensino-serviço. }\end{array}$ & 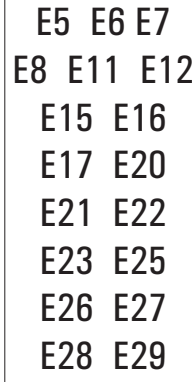 \\
\hline $\begin{array}{l}\text { DT3 - Papel dos diferentes } \\
\text { sujeitos e organizações } \\
\text { na mudança }\end{array}$ & $\begin{array}{c}\text { Fundamental papel dos docentes e da IES no processo } \\
\text { de mudança. } \\
\text { Necessidade de formação dos professores para o } \\
\text { exercício da docência. } \\
\text { Importância de ampliar parcerias entre IES e serviços } \\
\text { eassegurar o envolvimento de outras esferas da área da } \\
\text { saúde e da educação (integração ensino-serviço), além } \\
\text { da participação social. } \\
\text { Transformação dos poderes individuais em autoridade } \\
\text { compartilhada no processo (mesa de articulação e gestão). } \\
\text { EPS como estratégia de integração ensino-serviço-comunidade. } \\
\text { Necessidade de ter o usuário cada vez mais inserido no } \\
\text { contexto da formação. }\end{array}$ & \begin{tabular}{|ccc} 
E1 & E2 & E3 \\
E4 & E5 & E7 \\
E8 & E9 & E10 \\
E11 & E13 \\
E14 & E17 \\
E16 & E21 \\
E22 & E24 \\
E26 & E27 \\
E28
\end{tabular} \\
\hline
\end{tabular}

\section{Princípios e diretrizes do SUS como orientadores da formação}

Os princípios e diretrizes do SUS constituem as bases para o funcionamento e a organização desse Sistema no Brasil. $O$ arcabouço legal do SUS é constituído, fundamentalmente, por documentos que 
orientam sua estruturação e organização, tendo em vista a consolidação dos princípios e diretrizes definidos na Constituição Federal (BRASIL, 1988) e na Lei n. 8.080 (Lei Orgânica da Saúde) (BRASIL, 1990), esta última regulamentada recentemente pelo Decreto n. 7.508 (BRASIL, 2011).

No âmbito das políticas que regulamentam o SUS, cumpre destacar a Política Nacional de AB, tendo a ESF como eixo fundamental, que tem como objetivo desenvolver a atenção integral, com vistas a favorecer a autonomia das pessoas e impactar nos determinantes e condicionantes de saúde, contribuindo na melhoria da situação de saúde das coletividades (BRASIL, 2012). A integralidade é, de maneira geral, uma das diretrizes e princípios ressaltados no debate dos artigos incluídos na DT1 deste estudo, entendida como "um conjunto articulado e contínuo das ações e serviços preventivos e curativos, individuais e coletivos, exigidos para cada caso, em todos os níveis de complexidade do sistema" (BRASIL, 1990, $\mathrm{s} / \mathrm{p})$.

Nove publicações da DT1 abordam aspectos relacionados à concepção de saúde tratada nas IES, discutindo a necessidade de contemplar os princípios e diretrizes do SUS nas ações que visam à reorientação da formação profissional. Para três autores, o fato de a formação estar ancorada no modelo biomédico de ensino implica um grande obstáculo para a conformação de novas práticas (MORETTI-PIRES, 2009; FIUZA et al., 2011; GUARESCHI et al., 2009).

Ao debater a formação do médico, do enfermeiro e do odontólogo e sua adequação à visão ampliada de saúde e aos princípios do SUS, Moretti-Pires (2009) critica, em seu trabalho (E15), a formação fragmentada em especialidades, a qual não se pauta no enfrentamento dos determinantes sociais de saúde e tem pouca ênfase no SUS e na ESF. Há, nos processos de formação, insuficiente vivência prática em saúde na comunidade, indicando a priorização da técnica e do trabalho individual, focado na doença. Em alguns casos, as disciplinas que se referem à dimensão social estão desintegradas/dispersas ao longo do currículo.

Nessa mesma direção, Costa e Miranda (2009) (E17) realizam uma reflexão sobre a formulação da política de recursos humanos em saúde no Brasil, no que diz respeito à reorganização das instituições de ensino superior e à reorientação de novos modelos pedagógicos no desenvolvimento de profissionais de saúde, a partir dos problemas sociais da população e com vistas ao fortalecimento da ESF. Para esses autores, é necessário: 
[...] rediscutir o papel da educação nesse contexto e as suas respostas ao grande processo socioeconômico de mudança que afeta, num ritmo acelerado, todos os setores da sociedade, lembrando-se que um processo educativo não pode apenas se subordinar às exigências que as contingências histórico-produtivas impõem, mas deve ser um meio de alcançar as necessárias e eticamente exigidas mudanças no mundo do trabalho, para um exercício pleno da cidadania (COSTA; MIRANDA, 2009, p.505-506).

No estudo realizado na área de psicologia (E18), Guareschi et al. (2009) revelam que a influência da medicina no currículo representa a base da formação e da prática nessa área, ou seja, são priorizadas as pesquisas epidemiológicas em detrimento dos aspectos históricos e culturais sobre saúde, resultando em fragmentação disciplinar. Os currículos privilegiam a avaliação psicológica e as psicopatologias, ao invés da concepção de saúde implicada no cuidado e na promoção das condições de vida dos sujeitos. Para os autores:

O currículo é um campo em que estão em jogo múltiplos elementos, os quais estão implicados em relações de poder e compõem uma política cultural. Analisar os espaços institucionais de educação e seus currículos como 'territórios de produção, circulação e consolidação de significados, como espaços privilegiados de concretização da política de identidade' (COSTA, 1999, p.38), faz-nos pensar que quem tem força nessa política impõe ao mundo suas representações, isto é, propõe o universo simbólico de sua cultura particular (GUARESCHI et al., 2009, p.37).

Esses trabalhos convergem para o ideário de que a formação de recursos humanos orientada para o SUS nas IES apresenta desafios relacionados aos currículos rígidos que dificultam o processo educativo, às questões relacionadas ao próprio modelo de saúde biomédico, ainda hegemônico nos serviços e nas IES, e, principalmente, à falta de compromisso de todos os sujeitos envolvidos nesse processo. Mudanças efetivas no mundo do trabalho requerem movimentos que favoreçam o pleno exercício da cidadania, os quais se iniciam no mundo do ensino, sobretudo nos privilegiados espaços curriculares.

Nessa mesma ótica, o conjunto dos resultados da investigação (E23) de Costa e Miranda (2010) aponta que os Projetos Pedagógicos dos Cursos de graduação na área da saúde devem contemplar a divulgação e a reflexão crítica do SUS e seus princípios, para que os profissionais ou egressos possam colaborar com a construção de um sistema justo, digno, 
solidário, resolutivo, atendendo $₫$ integralidade, a qualidade e a humanização do atendimento. Seus achados levam a concluir que, apesar das boas intenções, os estudantes de enfermagem consideram que as estratégias de implementação se mostraram frágeis para dar conta da concretização do ideal expresso no Projeto Pedagógico: habilitar o enfermeiro para o SUS.

$\mathrm{Na}$ investigação (E30) de Fiuza e colaboradores (2011), são avaliadas as concepções e as dimensões relacionadas à $\mathrm{AB}$ junto a estudantes de odontologia de uma universidade pública no Brasil. Consideram que os princípios da $\mathrm{AB}$, como solidariedade, (co)responsabilidade, vínculo e capacidade de diálogo, são requisitos na atuação dos profissionais de saúde. $\mathrm{O}$ estudo revela que os profissionais continuam sendo formados em um modelo que não responde às necessidades e desafios exigidos pelo SUS. Sinaliza a importância da visão ampliada do processo saúde-doença, a partir de posturas profissionais adequadas para o trabalho na $A B$, sobretudo em relação dimensão "humanização", a qual valoriza a ética e a solidariedade, o vínculo e a responsabilização, nesse nível de atenção (FIUZA et al., 2011).

A revisão de literatura (E9) realizada por Araújo et al. (2007) discute a integralidade como eixo norteador na formação de profissionais de saúde. A formação, orientada nessa perspectiva, deve considerar como eixos norteadores para sua construção: a concepção integral do ser humano, a abordagem multidisciplinar, a atenção global, o desenvolvimento da capacidade de diálogo, a visão generalista, entre outros saberes da assistência individual e da saúde coletiva, dentre eles, a EPS e conhecimentos acerca do SUS e das políticas de saúde.

Para além da solidariedade, do trabalho em equipe, da humanização e da capacidade de diálogo, a formação orientada para a integralidade é considerada requisito fundamental na formação de recursos humanos para o SUS. A integralidade aparece nos trabalhos como importante princípio (re)orientador das práticas de saúde, a partir de sua inserção na Constituição Federal (BRASIL, 1988), quando se propõe que as ações e os serviços de saúde devem compor uma rede organizada segundo três diretrizes, uma delas sendo a integralidade da atenção. Formar profissionais nessa perspectiva significa não somente a ruptura do modelo de formação, mas também a (re)organização dos serviços e processos de trabalho.

O estudo transversal analítico (E25) de Coelho et al. (2011) demonstra que muitos dos profissionais atendem a atual proposta de 
atuação junto ao SUS, o que requer do cirurgião-dentista novas competências e habilidades, como a educação em saúde e a participação junto ao Conselho Municipal de Saúde. Isso se deve, entre outras coisas, às propostas dirigidas aos cursos da área da saúde, como o "Pró-Saúde, que tem a perspectiva de reorientar a formação em saúde, também em odontologia, incentivando a integração do ensino ao serviço público de saúde" (COELHO et al., 2011, p.70).

Alguns resultados também apontam para a necessidade de que iniciativas de formação permanente ocorram em consonância com as diretrizes da política nacional de saúde e voltadas aos desígnios do SUS, a partir de um modelo que envolva competência, técnica e resolutividade. Para os autores de um dos estudos (E12), "a falta de preparo e/ou capacitação é considerada pelos trabalhadores como uma situação angustiante, que dificulta a realização das atividades necessárias à saúde da população, bem como a resolução dos problemas diagnosticados na comunidade, gerando insatisfação no trabalho" (CAMELO; ANGERAMI, 2008, p.50).

$\mathrm{Na}$ literatura, ainda, encontrou-se algum destaque para a formação a partir de treinamento em serviço, caso do Programa de Aprimoramento Profissional, cuja experiência relatada teve como objetivo desenvolver modelos assistenciais em Terapia Ocupacional e criar novos projetos terapêuticos, pautados na demanda dos usuários dos serviços do SUS. O estudo (E19) afirma que o Programa ganhou destaque, como política pública estadual, para a formação continuada de profissionais (TOLDRÁ; MUÑOZ; PALM, 2009).

Os trabalhos organizados nessa DT confirmam que a mudança no modelo de atenção e nas práticas de saúde implica a reestruturação curricular, por meio de uma abordagem coerente com a integralidade e a resolutividade, sem deixar de lado aspectos como solidariedade, vínculo, trabalho em equipe, humanização e capacidade de diálogo, fortalecendo a atitude cidadã dos futuros profissionais. Os estudos abordam as políticas interministeriais como importantes movimentos que estão se conformando na direção de mudanças efetivas na formação de profissionais e, por conseguinte, no modelo assistencial. O Pró-Saúde, assim como o PETSaúde, na qualidade de dispositivos de reorientação da formação de profissionais da saúde, implicam, ainda, ações de EPS, ao considerarem a integração ensino-serviço-comunidade como pressuposto fundamental. 


\section{Necessidades do usuário e dos serviços de saúde}

No que se refere à ação educativa, o educador Paulo Freire argumenta sobre a necessidade de que educador e educando atuem como sujeitos de sua prática, criando-a e recriando-a por meio da ação-reflexãoação sobre o cotidiano, num movimento de permanente diálogo, e no qual os sujeitos são protagonistas (FREIRE, 2001; 2005). A conscientização implica desvelar a realidade, numa unidade indissolúvel entre a ação e a reflexão sobre essa realidade em transformação, da qual o homem participa como sujeito histórico. Reconhecer a realidade como passível de mudança torna os homens corresponsáveis em sua construção e transformação e, dessa forma, conscientes de sua capacidade de, em conjunto com outros, intervir sobre essa realidade (FREIRE, 2001).

Nessa ótica, também a PNEPS prevê a aprendizagem no trabalho, contexto em que "O aprender e o ensinar se incorporam ao cotidiano das organizações e ao trabalho. A educação permanente se baseia na aprendizagem significativa e na possibilidade de transformar as práticas profissionais" (BRASIL, 2007a, s/p).

A DT2 envolveu 18 estudos que tratam da necessidade de um perfil profissional generalista e conhecedor da realidade local na qual atua. Esses aspectos têm sido intensificados pelas iniciativas de aproximação entre os Ministérios da Saúde e da Educação, as quais implicam a integração ensino-serviço e a participação de outros setores, (co)responsáveis no processo. Os estudos demonstram preocupação com a formação de docentes voltados para essa lógica de atuação, bem como que utilizem metodologias de ensino baseadas no diálogo, que tendam à autonomia e à formação cidadã.

O estudo (E5) de Amoretti (2005) aborda a questão da educação médica no contexto das necessidades sociais de formação de recursos humanos para a organização do SUS. Refere que o treinamento e capacitação dos profissionais para o uso das tecnologias consagrou as residências médicas e a lógica da capacitação em serviço ancoradas no aumento da formação de especialistas, nos hospitais de ensino. A gestão politico-administrativa das instituições de saúde, públicas ou privadas, orientou-se, de maneira geral, por essa via. Considera importante ampliar as parcerias entre as instituições formadoras e assegurar o envolvimento de outras esferas da área da saúde e da educação, sem as 
quais a legitimidade do processo não ganha a força do valor legal e de diretriz de política pública.

Cotta e colaboradores (2007), em seu ensaio sobre a demanda por recursos humanos habilitados para atuar em situações de pobreza e desigualdade (E6), propõem a discussão sobre a formação profissional adequada às necessidades do sistema de saúde, considerando seus usuários e as condições de desigualdade e injustiça social. Para esses autores, aliar as competências dos trabalhadores de saúde às demandas das diferentes coletividades e condição real para a educação bem-sucedida no campo da saúde. Isso requer dos profissionais conhecer a realidade, adentrar na comunidade e "buscar delimitar seu papel, seu lugar e espaço no 'territorio-processo"' (COTTA et al., 2007, p.283).

É importante que se exercite, diuturnamente, a "arte da alteridade", ou seja, o abrir-se ao outro, às suas diferentes representações sociais e formas de enfrentamento das adversidades do cotidiano, movimento capaz de permitir a construção de novos significados (COT'TA et al., 2007, p.283).

Em sua revisão de literatura sobre a temática (E20), Almeida et al. (2010) afirmam que a transformação do modelo passa, necessariamente, pela sensibilização social do cirurgião dentista e pelo fortalecimento da cidadania por parte dos usuários.

Embora importantes no processo de construção do SUS, os instrumentos legais de controle e participação social são inócuos para uma sociedade alienada e, dessa forma, retarda as transformações necessárias ao sistema em desenvolvimento (ALMEIDA et al., 2010, p.128).

Esses e outros estudos dessa DT corroboram para a participação social nos movimentos de formação voltados à consolidação do SUS, por meio do reconhecimento das diversidades regionais e locais dos serviços e dos municípios. Destacam, ainda, o incentivo a práticas tecnoassistenciais e de gestão político-administrativa participativa e integrada entre os diferentes serviços de saúde.

Nessa perspectiva, estudo (E28) realizado com graduandos do Curso de Farmácia de uma universidade pública do Brasil sobre suas percepções em relação à assistência farmacêutica no serviço de saúde pública aponta o aspecto tecnicista hegemônico, ainda característico da educação e da prá- 
tica profissional farmacêutica tradicional, aspecto presente na motivação inicial dos estudantes para estudar farmácia (NICOLINE; VIEIRA, 2011).

Finkler e colaboradores (2011), em seu estudo (E27), referem que o MS implementa dispositivos de reorientação da formação, de maneira convergente com as DCN, o que facilita a inserção na rede de serviço. As mudanças na formação, de acordo com os autores, requerem democratização de espaços de poder e, por isso, os cursos precisariam investir não só no trabalho multiprofissional interdisciplinar e na efetiva integração ensino-serviço, mas também na atuação intersetorial, no controle social, na associação entre estudo e trabalho e na transformação do poder em autoridade compartilhada.

A integração poderá acontecer quando existir, tanto para a escola quanto para a rede, uma intencionalidade complementar e convergente, com objetivos comuns e peculiares, capazes de constituir espaços pedagógicos com vivências que possibilitem, para ambas, ganhos reais. Nesse contexto, a realidade que ensina é, ao mesmo tempo, objeto do aprendizado, gerando reflexão, crítica e autocrítica, constituindo-se no substrato fundamental à formação pessoal e profissional do acadêmico (WERNECK, et al., 2007 apud FINKLER; CAETANO; RAMOS, 2011, p.1.065).

Nessa mesma ótica, o relato de experiência do PET-Saúde (E29) confirma a relevância da ampliação dos cenários de prática e da criação de espaços de aprendizagem dialógicos para a "formação de médicos mais humanos, éticos, plenamente integrados ao SUS, preparados tanto para a prática profissional, quanto para os enfretamentos da vida, para a construção de um sistema de saúde que atenda às necessidades da população [...].” (DIAS et al., 2012).

Destaca-se, mais uma vez, a dimensão que vêm assegurando as Ações Estruturantes Interministeriais como dispositivos de incentivo à transformação do processo de geração de conhecimentos e prestação de serviços à população, com objetivo de corrigir o descompasso entre a orientação da formação dos profissionais de saúde e os princípios, diretrizes e necessidades do SUS. A inserção precoce dos estudantes no cenário real de práticas do SUS, a abordagem integral do processo saúde-doença e a ênfase na $A B$, desde o início da formação, favorecem a evolução do conhecimento, sobretudo, pela motivação e o despertar da consciência crítica dos sujeitos. 
Esses achados fazem refletir que a inserção do estudante na realidade dos trabalhadores do SUS favorece a formação de profissionais com perspectiva inovadora e abordagem crítico-reflexiva, pois permite o contato mais íntimo com a comunidade. Assim, a realidade vivenciada é refletida, podendo direcionar a transformação da prática, mediante a crítica e autocrítica, constituindo-se como elemento fundamental $₫$ formação pessoal e profissional do acadêmico. Cumpre destacar, nessa perspectiva, a integração ensino-serviço como fomentadora de tais possibilidades, ao aproximar os mundos do trabalho e do ensino em saúde, ambos inseridos no contexto concreto de vivência e convivência dos usuários.

\section{Papel dos diferentes sujeitos e organizações na mudança}

Ao compreender a sua condição de ser inacabado, o homem se torna ético e percebe que "os homens se educam entre si, mediatizados pelo mundo" (FREIRE, 2005, p.75). Nessa perspectiva, os pressupostos elucidados nas DCNs consideram como habilidade imprescindível ao futuro profissional da saúde a capacidade de aprender a aprender, além da responsabilidade de educar-se continuamente, tanto durante a sua formação, quanto durante a sua prática laboral (BRASIL, 2001).

Nos 20 estudos referentes à DT3, são abordados aspectos das Ações Estruturantes Interministeriais de Reorientação da Formação de profissionais da saúde, sobretudo em relação à contextualização histórica do processo e à importância de os diversos sujeitos estarem envolvidos efetivamente no processo. Abordam, ainda, a necessidade de investir-se na formação de professores para atuar nessa lógica, a partir de uma postura profissional condizente com a prática docente.

Entre as publicações, vale destacar o ensaio teórico (E1), realizado em 2002, por Ceccim e colaboradores (2002), o qual problematiza a identificação das intersecções Gestão em Saúde e Formação de Pessoal para o SUS, a partir da compilação de informações constantes na legislação do SUS e nos fóruns de participação em saúde. Na discussão que se faz presente no estudo, destacam-se os apontamentos dos autores sobre os elementos para a consolidação da interface formação-gestão, evidenciados durante a XI Conferência Nacional de Saúde, sobretudo, relacionados aos argumentos para o desenvolvimento de pessoal engajado no 
Controle Social em saúde. Nessa mesma Conferência, amplia-se o debate sobre os currículos de formação na área da saúde e reafirma-se a deliberação da X Conferência, sobre a revisão do currículo mínimo. "Em 2001, o Conselho Nacional de Educação substituiu o conceito de 'currículo mínimo' para as profissões superiores pelo conceito de 'Diretrizes Curriculares"'. Em relação à EPS, os participantes da XI Conferência destacaram a necessidade de as esferas de governo assumirem sua parcela de responsabilização com a formação e desenvolvimento de profissionais da saúde, ao destinarem financiamento para a qualificação de pessoal (CECCIM et al., 2002, p.381).

Esse resgate histórico permite perceber como vem ocorrendo, de forma gradativa, o envolvimento de outros setores na construção das políticas públicas que hoje regulamentam e conduzem a formação em saúde no Brasil.

Orientando-se por essa mesma linha de retrospectiva histórica, em 2003, Cutolo (2003) analisa, em seu trabalho (E3), a criação dos Polos de Educação Permanente, como um movimento rumo à execução da estratégia de formação de recursos humanos para o SUS, e propõe a busca de articulação intersetorial para a mudança nas esferas de formação e, por conseguinte, para a mudança do modelo de atenção. Considera que as mudanças nas práticas do SUS pressupõem uma articulação entre núcleo formador, rede de serviços, gestor profissional da saúde, comunidade e controle social. Essa relação não hierarquizada é baseada no princípio da roda, na qual a mesa de articulação constitui-se em espaço de planejamento, gestão de políticas educacionais, agregadoras e não fragmentadas.

A pesquisa (E2) de Freire et al. (2003) aponta dificuldades e desafios encontrados no decorrer do processo de mudança, rumo à consolidação do SUS. Dentre eles, refere a fundamental transformação das pessoas e suas percepções, a qual se tem mostrado difícil, lenta, conflituosa e complexa. Essa habilidade requer trabalhar dimensões como a subjetividade e a afetividade no cuidado, nas quais se revelam menor acúmulo de experiências. A resistência $₫$ mudança esta associada a diversas circunstâncias, como a falta de adesão ao referencial pedagógico por parte dos docentes, a perda de poder, a falta de responsabilidade e de apropriação em relação ao processo de mudança, a falta de habilidade na aplicação das novas tecnologias pedagógicas, entre outros. 
Ainda no que se refere à prática docente, os estudos revelam (E21, E28) que grande parte dos professores do ensino superior não teve em sua formação o adequado preparo para a docência. Preocupados com o "domínio de conteúdo", o corpo docente nem sempre consegue dar conta dos aspectos pedagógicos, o que exige condições de qualificação e desenvolvimento, para que o processo de ensino-aprendizagem seja mais efetivo (MORAES; LOPES, 2010; NICOLINE; VIEIRA, 2011).

Canônico e Brêta (2008) apontam, em seu trabalho (E11), que o grande desafio, na formação dos estudantes da área da saúde, para atuarem no SUS, encontra-se na tomada de consciência por parte dos docentes, sobre a premência de se instrumentalizar técnica, científica e politicamente os futuros profissionais, frente às questões sociais e políticas do país. A defesa do SUS, portanto, suscita o diálogo entre o potencial humano que o estudante tem, o conteúdo teórico-prático que lhe é oferecido na graduação e a sua participação em movimentos sociais organizados entre eles, o estudantil. Para tanto, são fundamentais os papéis desempenhados pelo professor e pela IES. Isso é reforçado em outro estudo (E16), que aponta como um dos desafios do SUS o trabalho em saúde, função que recai, também, sobre as instituições de ensino, principalmente, a universidade, como um desafio que exige redefinição de processos de formação e adequação dos currículos a partir dos projetos pedagógicos comprometidos com o SUS (MARTINS et al., 2009).

Apesar das prerrogativas legais de ordenação da formação em saúde direcionada para o SUS, alguns achados sinalizam um descompasso entre os requisitos da práxis profissional prevista para os profissionais e a política de saúde vigente no país. Nesse sentido, Farias e Silva (2008) apontam, em seu estudo (E13), que as bases conceituais, metodológicas e pedagógicas que sustentam os planos de ensino dos componentes curriculares nem sempre estão em sintonia com a práxis administrativa dos profissionais. Tal fato evidencia o papel secundário das escolas e da universidade, que deveriam posicionar-se $a$ frente dessa operação, por se tratar de locais nos quais, teoricamente, os processos reflexivos são mais considerados (FARIAS; SILVA, 2008).

De maneira semelhante a tais reflexões e destaques, o estudo (E14) de Barbosa e Viana (2008) reafirma o compromisso da formação com os princípios da Reforma Sanitária Brasileira e do SUS, declarados nas DCNs dos cursos de graduação e ancorados nas proposições de reo- 
rientação dos cursos de graduação, propostas pelos Ministérios da Saúde e da Educação. Os autores consideram que é possível mudar a lógica do ensino tradicional, centrado no professor e/ou nas tecnologias educacionais, a partir da diversificação do cenário de ensino, da adoção de metodologias ativas de ensino-aprendizagem e da articulação de instituições de ensino e de serviços, professores e estudantes, a fim de promover experiências intercursos.

Logo, um dos desafios propostos a partir da leitura desses trabalhos tem a ver com o preparo da IES para o apropriado envolvimento com as iniciativas de reorientação da formação de profissionais, bem como com a adequada formação docente para atuar nessa lógica. Os conhecimentos pedagógicos necessitam ser constantemente reconstruídos, num movimento educativo em permanente transformação. Confirmando as considerações encontradas, Haddad et al. (2008) também distinguem que a formação superior, na área da saúde, pressupõe o comprometimento das IES com as necessidades dos usuários do SUS, potencializado pela integralidade da atenção.

Por outro lado, o estudo (E22) de Moimaz et al. (2010) constata que os serviços de saúde colaboram, de forma importante, na discussão sobre a formação de recursos humanos, indicando deficiências na formação universitária e permitindo que mudanças e adaptações nos conteúdos curriculares sejam realizadas. Nessa direção, Cavalcanti e colaboradores (E26) refletem que a construção do SUS depende da articulação entre comunidade, governo e profissionais, interessados na qualificação e fortalecimento dos serviços de saúde e do próprio SUS (CAVALCANTI et al., 2010).

Em relação à Política Nacional de Educação Permanente em Saúde (PNEPS), Lopes et al. (2007) afirmam que, no Brasil, ela se expande para além da integração ensino-serviço, incluindo aspectos da dinâmica dos serviços, da participação social e da gestão do sistema de saúde vigente. Sinalizam, em seu estudo (E7), que isso justifica a participação dos atores sociais nas políticas intersetoriais. Esses sujeitos se transformam em autores das políticas em nível local. Por isso, essa política envolve não somente o desenvolvimento de profissionais de saúde que já estão trabalhando no SUS. Envolve também estudantes, docentes, gestores e a população, representada pelos diversos movimentos sociais ligados à saúde. 
Essas elucidações confirmam o importante papel dos diferentes sujeitos (comunidade, governo, instituições de ensino e profissionais) que se encontram em articulação no incentivo às práticas reorientadoras da formação e fortalecedoras do SUS. Nesse aspecto, as ideias convergem com a proposição sobre a importância da interação no processo de reorientação da formação na área da saúde, o chamado "quadrilátero da formação", formado pelos segmentos: formação/ensino, atenção/assistência, gestão e controle social (CECCIM; FEUERWERKER, 2004). Reforçam, ainda, a importância das ações de EPS como integradoras do mundo do trabalho e do mundo do ensino, beneficiando sujeitos de ambos e também o usuário.

Igualmente salientadores desse aspecto, alguns achados (E8) deixam bastante evidente que as ações de EPS, assim como outras iniciativas de integração ensino-serviço voltadas à qualificação profissional, se intensificaram com a aproximação do MS com o MEC, em 2003. Essa articulação ocorre a partir da constituição da SGTES e das iniciativas que envolvem o desenvolvimento individual e institucional dos serviços, da gestão setorial e do controle social, com vistas à transformação da organização do trabalho em saúde (VINCENT, 2007).

Ao analisar a relação ensino-serviço, o estudo (E14) de Batista e Gonçalves (2011) aponta para a existência de conflitos, por esta ser considerada, por vezes, como mera representação de diferentes saberes advindos de instituições distintas, com competências diferenciadas. Atualmente, com a abertura das IES para mudanças curriculares, as propostas de mudanças na formação estão mais articuladas entre si e com os diferentes sujeitos envolvidos e se constroem a partir da problematização das necessidades locais e dos seus diversos segmentos. Os autores ainda chamam a atenção para a criação das CIES, que, apesar dos esforços e das estratégias implantadas, "ainda não são espaços de integração e articulação de outras ações propostas pela SGTES junto às instituições de ensino (Pet-saúde; Pró-Saúde; UNA-SUS, etc.) (BATISTA; GONÇALVES, 2011, p.892). De maneira complementar, o trabalho (E10) relata a experiência de um Programa de Residência Médica e sinaliza que o trabalhador da saúde precisa ser capaz de "saber e fazer", a fim de desempenhar sua prática nos diferentes cenários (RIBEIRO, 2007).

Nessa mesma direção, ainda sobre a EPS, o estudo (E4), de Mancia e coparticipantes, enfatiza a diferença conceitual entre "Educação 
Continuada" e "Educação Permanente", salientando que o modelo convencional, orientador da primeira, compreende o trabalho como aplicação do conhecimento teórico especializado, enquanto na segunda, as demandas educativas ocorrem no processo de trabalho, como resultado da cultura e do cotidiano laboral. Faz um alerta em relação aos desafios da PNEPS, sinalizando que, no atual contexto:

[...] a Política de Educação Permanente em Saúde poderá ser deturpada com ações politiqueiras e setoriais, cabendo aos seus agentes estabelecer um processo educativo que possibilite aos indivíduos pensar por si mesmos, enfrentar as contradições da sociedade e utilizar as novas tecnologias para compreendê-la e transformá-la (MANCIA et al., 2004, p.610).

Para esses autores, no intuito de provocar mudanças no perfil do profissional, o MS propõe atividades práticas em todos os tipos de unidades de saúde, bem como em equipes multiprofissionais ao longo da graduação, com incentivo à adequada abordagem pedagógica e à articulação dos conhecimentos. Para tanto, a universidade assume papel fundamental (por meio da SGTES e da PNEPS) na orientação, incentivo e regulação da formação profissional, para que sejam formados profissionais com competência geral e capacidade de resolutividade, com garantia da atenção integral e da qualidade a saúde da população (MANCIA et al., 2004).

Em relação ao papel dos diferentes sujeitos e organizações no processo de mudança, chama a atenção a ênfase dos autores sobre a importância do envolvimento intersetorial e da comunidade como corresponsável na condução da reorientação da formação e dos processos de EPS. As Ações Estruturantes Interministeriais são evidenciadas como estratégia para assegurar a participação do "quadrilátero da formação", apontando como desafio o trabalho integrado e articulado com a PNEPS junto às instituições de ensino.

Cumpre destacar que, de maneira geral, foram recorrentes os indicativos de fragilidades e potencialidades de experiências e iniciativas de formação na área da saúde e as sugestões para pesquisas e discussões em torno da temática, como importante ferramenta para a qualificação das práticas em saúde pública. 


\section{Considerações finais}

As Dimensões Temáticas encontradas nos estudos relacionados à formação de profissionais de saúde orientada para o SUS salientam a importância da incorporação do ideário do Sistema nos processos de construção do conhecimento; a necessidade de uma aprendizagem fundamentada no contexto das necessidades sociais e nas vivências cotidianas do processo laboral; os diferentes papéis assumidos pelas instâncias envolvidas e (co)responsáveis no processo; e as Ações Estruturantes Interministeriais de Reorientação da Formação de profissionais da saúde como dispositivos interministeriais que favorecem as mudanças na formação, sobretudo, por meio da integração ensino-serviço e do envolvimento dos segmentos do "quadrilátero da formação". Esse ideário está ancorado no pressuposto de que a reorientação das práticas implica o melhor desempenho, não somente dos profissionais, mas também dos demais sujeitos envolvidos no processo (estudantes, docentes, gestores e a população).

Tanto as Ações Estruturantes, quanto a integração ensino-serviço foram temáticas recorrentes nas diferentes dimensões dos estudos analisados. São periódicas, ainda, as questões referentes à orientação teórica, mediante a adoção de propostas curriculares condizentes com a realidade vivenciada na prática do serviço, assim como à PNEPS, como elemento que tangencia as iniciativas de reorientação da formação, especialmente em nível de graduação, mas com reflexos significativos nas práticas educativas desenvolvidas junto aos serviços. Nesse sentido, cumpre destacar a importância das parcerias, em processos de educação e de cuidado, quando se valoriza o protagonismo dos sujeitos envolvidos, reconhecendo seu papel nos movimentos de transformação.

Recomenda-se realização e divulgação dos achados de pesquisa na modalidade de artigos, principalmente, analisando aspectos relacionados às Ações Estruturantes Interministeriais, a fim de contribuir para o fortalecimento desses dispositivos e fomentar o aprofundamento do debate sobre a temática.

Considerando que este estudo limitou-se a apresentar dimensões temáticas gerais dos trabalhos, sugere-se, como continuidade, a realização de uma análise mais aprofundada e crítica dos estudos. Fica a sugestão aos profissionais e docentes que estão envolvidos com esse processo de incentivarem a pesquisa, sobretudo, de cunho avaliativo, nessa área. 
As restrições do estudo são evidenciadas tendo em vista os próprios critérios de inclusão e exclusão na busca e o fato de terem sido pesquisadas algumas bases e descritores, o que, certamente, retrata apenas parte do universo da produção existente.

A revisão confirma o discurso sobre a importância da formação como operadora essencial das mudanças na prática de atenção à saúde. Tornar o tema prioridade nas agendas dos que conduzem e operam o SUS requer discutir a (co)responsabilização de todos que participam dos processos de formação e qualificação de profissionais e de gestores das práticas e dos serviços.

\section{REFERÊNCIAS}

ALMEIDA, A. B.; ALVES, M. S.; LEITE, I. C. G. Reflexões sobre os desafios da odontologia no sistema único de saúde. Rev. APS., Juiz de Fora/MG, v.13, n.1, p.126-132, 2010. ALMEIDA, A. H.; SOARES, C. B. A dimensão política do processo de formação de pessoal auxiliar: a enfermagem rumo ao SUS. Rev. Lat. Am. Enfermagem, Ribeirão Preto/SP, v.10, n.5, p.629-36, 2002.

AMÂNCIO FILHO, A., VIEIRA, A. L. S., GARCIA, A. C. P. Oferta das graduações em Medicina e em Enfermagem no Brasil. RBEM., Manguinhos/RJ, v.30, n.6, p.161-70, 2006.

AMORETTI, R. A educação médica diante das necessidades sociais em saúde. Rev. bras. educ. méd., Manguinhos/RJ, v.29, n.2, p.136-146, 2005.

ARAÚJO, D.; MIRANDA, M. C. G.; BRASIL, S. L. Formação de profissionais de saúde na perspectiva da integralidade. Rev. baiana saúde pública, Salvador/BA, v.31, n.1, p.20-31, 2007.

BARBOSA, E. C. V.; VIANA, L. O. Um olhar sobre a formação do enfermeiro/docente no Brasil. Rev. Enferm. UERJ., Rio de Janeiro, v.16, n.3, p.339-4, 2008.

BATISTA, K. B. C.; GONÇALVES, O. S. J. Formação dos profissionais de saúde para o SUS: significado e cuidado. Saúde Soc., São Paulo, v.20, n.4, p.884-899, 2011.

BRASIL. Congresso Nacional. Constituição da República Federativa do Brasil. Promulgada em 05 de outubro de 1988. [documento internet] 1988. Disponível em: $<$ http://www.planalto.gov.br/legislacao/>. Acesso em: 12 set. 2008.

BRASIL. Ministério da Saúde. Lei n. 8.080, de 19 de setembro de 1990. Dispõe sobre as condições para a promoção, proteção e recuperação da saúde, a organização e o funcionamento dos serviços correspondentes e dá outras providências. [documento internet] 1990. Disponível em: <http://portal.saude.gov.br>. Acesso em: 14 out. 2013.

BRASIL. Ministério da Saúde. Ministério da Educação. Resolução CNE/CES n.1133 de 2001. Diretrizes Curriculares Nacionais dos Cursos de Graduação em Enfermagem, Medicina e Nutrição. Diário Oficial da União, Brasília, 03 de outubro de 2001. Seção 1E, 
p.131. Disponível em: <http://portal.mec.gov.br/cne/arquivos/pdf/CES1133.pdf>. Acesso em: 15 ago. 2012.

BRASIL. Ministério da Saúde. Portaria GM/MS n. 198/04, de 13 de fevereiro de 2004: institui a Política Nacional de Educação Permanente em Saúde como estratégia do Sistema Único de Saúde para a formação e o desenvolvimento de trabalhadores para o setor e dá outras providências. Brasília: Ministério da Saúde, 2004a.

BRASIL. Ministério da Saúde. Secretaria de Gestão do Trabalho e da Educação na Saúde (SGTES). Departamento de Gestão da Educação na Saúde (Deges). Política de Educação e Desenvolvimento para o SUS: caminhos para a educação permanente em saúde - Polos de educação permanente em saúde. Brasília: Ministério da Saúde, 2004b. (Série C. Projetos, Programas e Relatórios).

BRASIL. Ministério da Saúde. Diretrizes operacionais: pactos pela vida, em defesa do SUS e de gestão. Brasília: Ministério da Saúde, 2006. Série Pactos pela Saúde, v. 1.

BRASIL. Ministério da Saúde. Portaria GM/MS n. 1.996/07, de 20 de agosto de 2007: dispõe sobre as diretrizes para a implementação da Política Nacional de Educação Permanente em Saúde. Brasília: Ministério da Saúde, 2007a.

BRASIL. Ministério da Saúde. Ministério da Educação. Programa Nacional de Reorientação Profissional em Saúde - Pró-Saúde: objetivos, implementação e desenvolvimento potencial. Ministério da Saúde, Ministério da Educação. Brasília, 2007b.

BRASIL. Ministério da Saúde. Decreto n. 7.508, de 28 de junho de 2011. Regulamenta a Lei n. 8.080, de 19 de setembro e 1990, para dispor sobre a organização do Sistema Único de Saúde - SUS, o planejamento da saúde, a assistência à saúde e a articulação interfederativa, e dá outras providências. [documento internet] 2011a. Disponível em: <http://www.conasems.org.br/site/index.php/juridico/leis-e-decretos>. Acesso em: 22 abr. 2012.

BRASIL. Ministério da Saúde. Secretaria de Atenção à Saúde. Departamento de Atenção Básica. Política Nacional de Atenção Básica. Série E, legislação em saúde. Brasília, DF: Ministério da Saúde, 2012.

CAMELO, S. H. H.; ANGERAMI, E. L. S. Formação de recursos humanos para a Estratégia de Saúde da Família. Cienc Cuid Saúde, Maringá/PR, v.7, n. 1, p.45-52, 2008.

CANÔNICO, R. P.; BRÊTAS, A. C. P. Significado do Programa Vivência e Estágios na Realidade do Sistema Único de Saúde para formação profissional na área de saúde. Acta Paul Enferm, São Paulo, v.21, n.2, p.256-261, 2008.

CAVALCANTI, Y. W.; CARTAXO, R. O.; PADILHA, W. W. N. Educação odontológica e sistema de saúde brasileiro: práticas e percepções de estudantes de graduação. Arq Odontol, Manguinhos/RJ, v.46, n.4, p.224-231, 2010.

CECCIM, R. B.; ARMANI, T. B.; ROCHA, C. F. O que dizem a legislação e o controle social em saúde sobre a formação de recursos humanos e o papel dos gestores públicos, no Brasil. Ciênc. saúde coletiva, Manguinhos/RJ, v.7, n.2, p.373-383, 2002.

CECCIM, R. B., FEUERWERKER, L. C. M. O quadrilátero da formação para a área da saúde: ensino, gestão, atenção e controle social. PHYSIS: Revista Saúde Coletiva, Rio de Janeiro, v.14, n.1, p.41-65, 2004.

COELHO, M. Q.; COSTA, S. M.; MARTELLI, D. R. B.; MARTELLI JÚNIOR, H.; BONAN, P. R. F.; FRANCY, S. A. Odontologia no contexto do sistema único de saúde de Montes Claros, Minas Gerais. Arq Odontol, Belo Horizonte, v.47, n.2, p.65-72, 2011. 
COSTA, R. K. S.; MIRANDA, F. A. N. Formação profissional no SUS: oportunidades de mudanças na perspectiva da Estratégia de Saúde da Família. Trab. Educ. Saúde, Rio de Janeiro, v.6, n.2, p.503-517, 2008/2009.

COTTA, R. M. M.; GOMES, A. P.; MAIA, T. M.; MAGALHÃES, K. A.; MARQUES, E. S.; SIQUEIRA-BATISTA, R. Pobreza, injustiça e desigualdade social: repensando a formação de profissionais de saúde. Rev. bras. educ. méd., Manguinhos/RJ, v.31, n.2, p.278286, 2007.

CUTOLO, L. R. A. O SUS e a formação de recursos humanos. ACM arq. catarin. med, Florianópolis, v.32, n.2, p.49-59, 2003.

DIAS, C. M. G. C.; SIQUEIRA, M. R. L.; LESSA, L. P.; MOREIRA, T. S.; FREITAS, R. T.; SOUSA, B. I. C. et al. O PET-Saúde como ferramenta estratégica de implantação de um curso de Medicina em uma universidade pública: relato de uma experiência. Rev. bras. educ. méd., Manguinhos/RJ, v.36, n.1, p.76-79, 2012.

FARIAS, L. D.; SILVA, C. C. Administração em Enfermagem: desvelando as bases conceituais, metodológicas e pedagógicas de seu ensino em João Pessoa - PB. Cienc Cuid Saúde, Maringá/PR, v.7, n.1, p.37-44, 2008.

FERRAZ, F.; BACKES, V. M. S.; MERCADO-MARTÍNEZ, F. J.; PRADO, M. L. Políticas e programas de educação permanente em saúde no Brasil: revisão integrativa de literatura. Sau e Transf. Soc., Florianópolis, v.3, n.2, p.113-128, 2012.

FINKLER, M.; CAETANO, J. C.; RAMOS, F. R. S. Integração "ensino-serviço" no processo de mudança na formação profissional em Odontologia. Interface comum. Saúde educ, Botucatu/SP, v. 5, n.39, p.1053-67, 2011.

FIUZA SANCHEZ, H.; SILVA, C. J. P.; DRUMOND, M. M.; FERREIRA E FERREIRA, E. A formação de valores e a prática da atenção primária na saúde com estudantes de odontologia. Acta Bioethica, Santiago/Chile, v.18, n.1, p.101-109, 2012.

FREIRE, P. Conscientização: teoria e prática da libertação: uma introdução ao pensamento de Paulo Freire. São Paulo: Centauro, 2001.

FREIRE, P. Pedagogia do oprimido. 41ed. Rio de Janeiro: Paz e Terra, 2005.

FREIRE, R. P.; GUIMARÃES, R. M.; HENRIQUES, R. L. M.; MAURO, M. Y. C. O currículo integrado da Faculdade de Enfermagem UERJ: uma reflexão sobre a formação de recursos humanos para o SUS. Rev Bras Enferm, Brasília, v.56, n.4, p.381-384, 2003. GANONG, L. H. Integrative reviews of nursing. Rev Nurs Health., Índia, v.10, n.1, p.1$11,1987$.

GUARESCHI, N. M. F.; DHEIN, G.; REIS, C.; MACHRY, D. S.; BENNEMANN, T. A formação em Psicologia e o profissional da saúde para o SUS (Sistema Único de Saúde). Arq. Bras. Psicol., Rio de Janeiro, v.61, n.3, p.35-45, 2009.

HADDAD, A. E.; BRENELLI, S. L.; PASSARELLA, T. M.; RIBEIRO, T. C. V. Política Nacional de Educação na Saúde. Rev. Baiana de Saúde Pública, Salvador, v.32, n.1, p.98-114, 2008.

LOPES, S. R. S.; PIOVESAN, E. T. A.; MELO, L. O.; PEREIRA, M. F. Potencialidades da educação permanente para a transformação das práticas de saúde. Com. Ciências Saúde, Brasília, v.18, n.2, p.147-55, 2007.

MANCIA, J. R.; CABRAL, L. C.; KOERICH, M. S. Educação permanente no contexto da enfermagem e na saúde. Rev Bras Enferm, Brasília, v.57, n.5, p.605-610, 2004.

MARTINS, R. J.; MOIMAZ, S. A. S.; GARBIN, C. A. S.; GARBIN, A. J. I.; LIMA, D. 
C. Percepção dos coordenadores de saúde bucal e cirurgiões-dentistas do serviço público sobre o Sistema Único de Saúde (SUS). Saúde Soc., São Paulo, v.18, n.1, p.75-82, 2009. MOIMAZ, S. A. S.; SALIBA, N. A.; ZINA, L. G.; SALIBA, O.; GARBIN, C. A. S. Práticas de ensino-aprendizagem com base em cenários reais. Interface comun. Saúde educ, Botucatu/SP, v.14, n.32, p.69-79, 2010.

MORAES, J. T.; LOPES, E. M. T. A formação de profissionais de saúde em instituições de ensino superior de Divinópolis, Minas Gerais. Trab. Educ. Saúde, Rio de Janeiro, v.7, n.3, p.435-444, 2010.

MORETTI-PIRES, R. O. Complexidade em Saúde da Família e formação do futuro profissional de saúde. Interface comun. Saúde educ, Botucatu/SP, v.13, n.30, p.153-66, 2009.

MOROSINI, M. V. G. C.; CORBO, A. D. A. (Orgs.). Modelos de atenção e a saúde da familia. Rio de Janeiro: EPSJV/Fiocruz, 2007. Disponível em: http://www.epsjv.fiocruz.br/ index.php?Area $=$ Material $\& M N U=\&$ Tipo $=1 \& N u m=26$.

NICOLINE, C. B.; VIEIRA, R. C. P. A. Assistência farmacêutica no Sistema Único de Saúde (SUS): percepções de graduandos em Farmácia. Interface comun. Saúde educ, Botucatu/SP, v.15, n.39, p.1.127-1.141, 2011.

RIBEIRO, E. C. O. Programas de residência médica em oncologia orientados por competência: trajetória de uma construção coletiva. Rev. bras. cancerol, Rio de Janeiro, v.53, n.1, p.99-118, 2007.

TOLDRÁ, R. C.; MUNÕZ PALM, R. D. C. Programa de Aprimoramento Profissional em Terapia Ocupacional. Rev. Ciênc. Méd., Campinas/SP, v.18, n.3, p.131-141, 2009.

VINCENT, S. P. Educação Permanente: componente estratégico para a implementação da política nacional de atenção oncológica. Rev. bras. cancerol, Rio de Janeiro, v.53, n.1, p.79-85, 2007.

Recebido em: 07/07/2013

Aprovado em: 20/12/2013

Contato:

Rua Martinho Lutero, 975E

Bairro São Cristóvão

CEP 89803-300

Chapecó | SC | Brasil 